\title{
Shotgun Metagenomics evaluation of soil fertilization effect on the rhizosphere viral community of maize plants
}

Nwabunwanne Lilian Nwokolo

University of Fort Hare

MATTHEW Chekwube ENEBE ( $\nabla$ enebematthew@gmail.com )

North-West University Potchefstroom Campus: North-West University https://orcid.org/0000-00030865-8336

\section{Research Article}

Keywords: Agricultural crops, bacteriophage community, metagenomics, soil fertilization, viral diversity

Posted Date: April 21st, 2021

DOI: https://doi.org/10.21203/rs.3.rs-391459/v1

License: (c) (i) This work is licensed under a Creative Commons Attribution 4.0 International License.

Read Full License

Version of Record: A version of this preprint was published at Antonie van Leeuwenhoek on November 11th, 2021. See the published version at https://doi.org/10.1007/s10482-021-01679-4. 


\section{Abstract}

The need for sustainability in food supply has led to progressive increase in soil nutrient enrichment. Fertilizer application affect both biological and abiotic processes in the soil, of which bacterial community that support viral multiplication are equally influenced. Soil viral community composition and dynamics are affected by soil fertilization with less exploration on organic and inorganic fertilizer application. In this study, we evaluated the influence of soil fertilization on the maize rhizosphere viral community growing in Luvisolic soil. The highest abundance of bacteriophages were detected in soil treated with high compost manure (Cp8), low inorganic fertilizer (N1), low compost (Cp4) and control (Cn0). Our result showed higher frequency of Myoviridae (47\%), Podoviridae (46\%) and Siphoviridae $(90 \%)$ in high organic manure (Cp8) fertilized compared to others. While Inoviridae (98\%) and Microviridae (74\%) were the most abundant phage families in low organic (Cp4) fertilized soil. This demonstrate that soil fertilization with organic manure increases the abundance and diversity of viruses in the soil due to its soil conditioning effects.

\section{Introduction}

Viruses inhabit every ecosystems and the level of abundance of these obligate intracellular parasite is dependent on the population of their susceptible host bacteria. Soil viruses particularly phages influence the bacterial community dynamics, ecological and evolutional dynamics. They achieve this through lysis and lysogenic conversion of which in some situations result in community breakdown of the microecosystem in the soil (Free et al. 2018; Braga et al. 2020; Liang et al. 2019). Phages activities in soil has led to disease suppression and control of pathogenic bacteria (Zaczek-Moczydłowska et al. 2020). However, they equally have a negative implication in biogeochemical cycling of nutrients by soil dwelling bacteria. The most susceptible bacteria (belonging to Acidobacteria, Bacilli, Verrucomicrobia, Proteobacteria and Gamma-Proteobacteria) which participate in the biogeochemical cycling of nutrients are often invaded by phages in the soil (Emerson et al. 2018; Woodcroft et al. 2018). Phages in any given habitat have been found to exceed bacterial population by 20 folds or by a factor of 5 to 25 . Thus, making them the most abundant entity in the biosphere (Heyer et al. 2019; Fuhrman 1999). The most abundant phage families in the soil are Podoviridae, Myoviridae, Mimiviridae, Siphoviridae as well as Phycodnaviridae. Among these viral families, Podoviridae, Siphoviridae and Myoviridae are the predominant bacteriophages at the soil subsurface (B horizon, characterized by high bacterial abundance). They are double stranded DNA viruses, majority of which are lytic phages (Liang et al. 2019; Adriaenssens et al. 2017; Trubl et al. 2018).

The abundance of phages varies across soil in different environment, soil usage and ecosystem. Agricultural soil for instance has an abundance of phages that ranges from $1 \times 10^{6}$ to $1 \times 10^{8} \mathrm{gram} / \mathrm{dry}$ weight. Forest soil has $5.8 \times 10^{9} \mathrm{gram} / \mathrm{dry}$ weight and hot desert soils have between $1 \times 10^{3}$ to $1 \times 10^{7}$ gram/dry weight (Williamson et al. 2017). These variations are attributed to the soil nutrients compositions (soil organic matter). Soil organic matter has shown to influence the abundance of soil bacteria as well as phage communities (Williamson et al. 2005; Zhuang and Jin 2003). Notwithstanding, 
a detailed knowledge of phage communities present in agricultural soil (particularly the rhizosphere of maize) under organic and inorganic fertilization are yet to be fully addressed.

Rhizosphere is the soil area under the influence of plants' root exudates and are characterized by high abundance of bacteria, fungi, protozoan, oomycetes, and nematodes. This region of the roots-soils interface has a dynamic and complex ecosystem with an abundance of bacteriophages (Enebe and Babalola 2020; Philippot et al. 2013; Chen et al. 2014). These microbes benefit from plants nutritionally and in return influence plants growth. In addition, they aid in organic matter breakdown (or nutrients mineralization), plant protection against pathogens invasion and plant tolerance to abiotic stress (Ramírez et al. 2020; Enebe and Babalola 2019, 2018).

Soil fertilization influences soil pH and availability of soil organic matter which affect the abundance of soil dwelling microbes (Zhuang and Jin 2003). Inorganic fertilizer could negatively affect the nutrient uptake by plants, soil pH, soil organic matter as well as the soil microbes. This effect is more on application of a high dose of inorganic fertilizer and under continuous usage (Six et al. 2004). Hence, there is a need to revert to the use of organic fertilizer in soil nutrient enrichment. Studies have reported that organic manure is efficient in promoting soil health, soil microbial biomass and abundance of microbes better than inorganic fertilization (Chu et al. 2007; Zhang et al. 2012). However, a recent study by Chen et al. (Chen et al. 2014) has shown that soil fertilization significantly increase the bacterial and phage population in the soil. To date, no study has examined the influence of soil fertilization on the maize rhizosphere phage communities and this forms the rationale behind our study. In this study, a farmland fertilized with different quantities of organic and inorganic fertilizers located in molelwane, North-West province of South Africa was selected. Here we evaluated the effects of soil fertilization with inorganic and organic manure on the abundance, frequency and diversity of maize rhizosphere bacteriophages. Our study have shown the correlation between phages abundance and soil fertilization at the maize rhizosphere.

\section{Materials And Methods}

\section{Experimental setup, DNA extraction and sample collection}

The setup of this experiment was done as previously described in Enebe and Babalola (Enebe and Babalola 2021) and the samples were collected as described by Musyimi et al. (Musyimi et al. 2018) and Zhang et al. (Zhang et al. 2013). Rhizosphere soil samples were collected from maize farmland located in Molelwane, North-West Province of South Africa. The soil samples was collected from a seven (7) weeks old growing maize plants (Zea mays averta) in fertilized and unfertilized soils using $5 \mathrm{~cm}$ auger ( 5 treatments $\times 3$ replicates plots per treatment). The soil was treated with $120 \mathrm{~kg} / \mathrm{ha}$ and $60 \mathrm{~kg} / \mathrm{ha}$ inorganic fertilizers and another set with 8 tons/ha and 4 tons/ha compost manure. The collected soil samples were put in a plastic bag and transported to the laboratory in an ice filled box. Community DNA was isolated from the soil samples using a PowerSoil isolation kit from MO Bio lab, Inc. USA as directed by the manufacturer. 


\section{Sequencing procedure}

The quantity of the DNA was measured using Qubit® dsDNA HS Assay Kit (Life Technologies) and processed using Nextera DNA Flex library preparation kit in line with the manufacturer's instruction (Illumina Inc.). DNA (50 nanogram in quantity) was used for the preparation of the libraries alongside fragmentation and addition of adapter sequences in the process. Adapter sequences and indices were added, following PCR cycles and the quantity of the generated libraries was measured using Qubit $\circledast$ dsDNA HS Assay Kit and the average libraries sizes was determined using Agilent 2100 Bioanalyzer. The libraries was pooled in an equal-molar ratios and sequenced pair end reads on a NovaSeq 6000 machine (Illumina) for 300 cycles at Mr DNA molecular Laboratory (USA).

\section{Processing of Sequences, Annotation and Statistical analysis}

The shotgun metagenomics reads obtained was uploaded in MG-RAST (Meyer et al. 2008) where quality filtering of the reads was performed to remove host-specific sequences, artificial reads, and ambiguous bases. Reads annotation was performed through blasting (using BLAST-like alignment tool algorithm) against M5NR databases (Kent 2002) and RefSeq databases (Wilke et al. 2012) by applying the default settings. The viral families and genus were analysed. The sequences was used for statistical analysis by performing one way analysis of variance (ANOVA) to check its significance. Abundance and distribution of the viral families and genus was visualized in pie chart and bar chart using Microsoft Excel. Simpson, Evenness and Shannon diversity indices was determined for the sample and contrasted among the treatments and control using Kruskal Wallis test. The viral beta diversity was examined using PCoA principal coordinate analysis on Eclidean distance matrix. Principal component analysis and principal coordinate analysis was analysed using default settings on CANOCO v5 (Microcomputer Power, Ithaca, New York). All the above mentioned statistical analysis was performed using PAST version 4.0 (Hammer et al. 2001) and the sequenced reads were deposited on NCBI with accession number PRJNA607213.

\section{Result}

\section{Fertilization effects on maize rhizosphere viral community structure}

At the various fertilization treatments, Bray Curtis similarity matrix and principal coordinate analysis was calculated to evaluate the viral community of maize rhizosphere. Viral community could be separated according to the treatment in major clusters of three (Fig. 1) with $\mathrm{Cn} 0$ and N1 clustering at left and N2 and $\mathrm{Cp} 4$ clustering at the right-hand side. The treatment $\mathrm{Cp} 8$ is widely separated from the clusters. The axis one correspond to a variation of 82.65 percent variation and separated the samples according to the fertilizers treatments (organic and inorganic fertilization).

The treatments effects on the viral community structure was shown by the principal component analysis, depicting the distribution of the viral genus according to the treatments (Fig. 2). The 8 tons per hectare compost treated soil, $60 \mathrm{~kg}$ per hectare inorganic fertilizer, control and 4 tons per hectare compost manure selected and enriched predominant bacteriophages in the maize rhizosphere than the $120 \mathrm{~kg}$ per 
hectare inorganic fertilized soil. In the PCA plot, Circovirus, Begomovirus, Nanovirus, Inovirus, PhiKvirus, T5-like virus etc. are the forces that separate the $\mathrm{N} 2$ and $\mathrm{Cp} 4$ from the control and treated samples. While N4-like virus, Mastrevirus and Chlorovirus are the forces the separate N2 and Cp4 samples. The factors along the negative values of axis 1 distinguished the $\mathrm{Cp} 8$ from $\mathrm{N} 1$ and $\mathrm{Cn} 0$. Axis 1 of the principal component analysis of the viral genus shows a strong positive loadings for Circovirus, Babuvirus, Bdellomicrovirus, Spiromicrovirus, Nanovirus, Inovirus, Norovirus etc. and a strong negative loadings for T7-like virus, PhiC virus, Bpp-virus, T4-like virus, SP01-virus, and Potyvirus. This viral analysis reflects strong bacteriophage abundance at negative axis 1 , which guarantee adequate plants protection. Their presence is positively correlated with the bacterial abundance as reported elsewhere by Enebe and Babalola (Enebe and Babalola 2020). Also, there is an increase in the abundance of animals and birds disease causing Circovirus (Gillespie et al. 2009), plant disease causing Babuvirus, Begomovirus and Nanovirus (Lal et al. 2020; Fiallo-Olivé and Navas-Castillo 2020), bacteria infecting Bdellomicrovirus, Spiromicrovirus and Inovirus (Hyman and Abedon 2012; Roux et al. 2019) and human disease causing Norovirus (Robilotti et al. 2015). At axis 2, there is a strong positive loadings for N4-like phages, monocotyledonous plants infecting Mastrevirus and algae infecting Chlorovirus (Van Etten et al. 2020; Buttimer et al. 2018; Claverie et al. 2019). These viruses particularly the phages and other bacteria infecting viruses are responsible for controlling bacterial phytopathogens and ensuring adequate plants protection in the fertilized soils.

There is high percentage abundance of bacteriophages such as SPO1-like viruses N1 samples. T4-like viruses, Bpp-1-like viruses, N4-like viruses, T7-like viruses and PhiC31-like viruses in Cp8 samples. phiKMV-like viruses, and Inovirus are predominant phages in the Cp4 samples. It was only Cp4 and Cp8 that bears approximately equal percent abundance of T5-like viruses in the maize rhizosphere (Fig. 3).

\section{The diversity of viruses in the maize rhizosphere at different soil fertilization}

The classification of phages according to their morphological types (Ackermann 2009), showed that Myoviridae, Podoviridae and Siphoviridae (all tailed phages) are dominant in Cp8 than in other rhizosphere samples. While Inoviridae and Microviridae are the dominant bacteriophages in Cp4 samples than in other samples (Fig. 4). The frequency of Siphoviridae viruses (90\%) was significantly higher in high compost manure amended soils, whereas Inoviridae viruses $(98 \%)$ has the highest frequency of occurrence in low compost manure treated soils (Cp4). The calculated viral diversity for all the viruses using Simpson and Shannon diversity indices showed that $\mathrm{Cp} 8, \mathrm{~N} 1$ and $\mathrm{Cn} 0$ rhizosphere soil samples was the highest, while that of $\mathrm{Cp} 4$ was the lowest among the various treatments. The Kruskal Wallis test $(P=0.0061)$ revealed a significant difference in the rhizosphere soil samples viral diversity. The N1 and $\mathrm{CnO}$ samples according to the calculated Evenness, revealed an evenly distributed viral community in the maize rhizosphere samples (Fig. 5). The phages families' diversity indexes are contained in Table 1 and did not differ significantly $(P>0.05)$.

\section{Discussion}


To ensure adequate supply of food, agricultural practices of supplying nutrients through soil fertilization has been on the increase. Agricultural soils are fertilized with organic and inorganic fertilizers to boost crop yield and soil fertility. Organic fertilizer has been found to support a balanced microbial growth and crop yield. While inorganic fertilizer support only the crop yield but on a small application. In this study, organic fertilizer enhanced the abundance of bacteriophages and other viruses in the maize rhizosphere (Fig. 3). Bacteriophages are viruses that prey on bacteria and are implicated in both ecological and evolutional changes among bacteria community in the soil (Williamson et al. 2017; Marcó et al. 2015). Bacteriophage abundance varies from one ecosystem to another, for instance, agricultural soil has between $1 \times 10^{6}$ to $1 \times 10^{8}$ gram dry weight ${ }^{-1}$ (Williamson et al. 2017), desert soil has about $2.2 \times 10^{3}$ gram per dryweight (Gonzalez-Martin et al. 2013), and forest soil has about $5.8 \times 10^{9}$ gram per dryweight (Helsley et al. 2014).

The abundant viruses like family's dominant in the maize rhizosphere under soil fertilization belongs to myoviridae (phages with long contractile tails), Siphoviridae (phages with long non-contractile tails), Inoviridae (filamentous phages), Podoviridae (phages with short non-contractile tails) and Microviridae (phages that are morphologically spherical and small bearing single stranded DNA) (Williamson et al. 2005). In our study, tailed phages were dominated in organic manure fertilized soils with very high distribution frequency (Fig. 4). This was in agreement with Chen et al. (Chen et al. 2014) which reported that organic manure-chemical fertilized soils increased the phages abundance in the soil by a factor of 4 times (13.1 x $10^{7}$ VLP per gram of soil) higher than inorganic fertilized soils. They also reported high distribution frequency of Myoviridae (viruses) in organic manure fertilized soils. The effects of organic manure on soil phages communities was observed in a pasture soil were cow dungs support the proliferation of soil bacteria. The increase bacterial hosts resulted in an increase in soil phage populations as reported by Narr et al. (Narr et al. 2017). Therefore change in the phages abundance resulted in change in bacterial respiration and abundance in the fertilized soils (Srinivasiah et al. 2015). Our study showed a significant increase in bacterial population but the result was report elsewhere (Enebe and Babalola 2021). The rationale behind increase in phages abundance in an organic manure fertilized soil could be attributed to its nutrient enrichment effects on the soil, increase in soil structure, soil air and water holding-capacity of the fertilized soil (Palaniveloo et al. 2020). It also reduced the electrostatic binding capacity of viruses and bacteria to clay minerals and soil particles (Kimura et al. 2008), making the availability of phages to infect bacteria and multiply in numbers. In another study by Doan et al. (Doan et al. 2014), organic fertilizer supported an increase in soil viral abundance by 8 to 12 folds.

Bacteriophages in the soil performs myriad of functions such as bacterial population control, suppression of phytopathogens, change in bacterial metabolism, transfer of genes from one bacteria to another and influence on biogeochemical cycling of nutrient through cell lysis and release of trapped nutrients as well as in fitness tradeoff of the hosts (Zheng et al. 2019; Emerson et al. 2018; Rabiey et al. 2020). 
At the genus level, SP01-like viruses prevailed more in N1 $(60 \mathrm{~kg} / \mathrm{ha}$ inorganic fertilizer) soil samples. T4like viruses, Bpp-1-like viruses, N4-like viruses, T7-like viruses and PhiC31-like viruses are present in Cp8 (8 tons/ha compost) samples. While phiKMV-like viruses, and Inovirus are predominant phages in the Cp4 (4 tons/ha compost). T5-like viruses occur mostly in Cp8 and Cp4 samples. T4-like viruses are lytic phages in the family, myoviridae. They have large double stranded DNA and perform nucleotide metabolism functions as well as DNA replisome (Ackermann and Krisch 1997; Tétart et al. 2001; Miller et al. 2003). Bpp-1-like viruses are members of Podoviridae with double stranded DNA with short noncontractile tails. They infect the bacteria Bordetella (Dai et al. 2010). PhiKMV-like viruses are lytic phages that infect Pseudomonas aeruginosa. They are members of the family Podoviridae with short noncontractile tails and double stranded DNA (Yu et al. 2017). Another important Podoviridae viruses are T7like viruses. They are lytic phages with short non-contractile tail and possess an icosahedral capsid and small genome (made of double stranded DNA) (Attai and Brown 2019; Pajunen et al. 2002). PhiC31-like viruses are yet another important phages that infect a wide range of bacteria (Bacillus, Arthrobacter, Lactobacillus, Escherichia, Staphylococcus, Mycobacterium etc.). They possess double stranded DNA molecules (Suárez et al. 1992; Smith et al. 1999). T5-like viruses on the other hand are members of the siphoviridae family and infect bacteria belonging to Enterobacteriaceae. They are characterized with long non-contractile tails and an icosahedral head that is isometric in shape (Sváb et al. 2018; Zivanovic et al. 2014). A very important phage that infect gram positive bacteria (such as Bacillus, Enterococcus, Staphylococcus, Brochothrix, Streptococcus etc.) are SP01-like viruses. These phages belong to the family, myoviridae and are lytic phages. They have an icosahedral head and long contractile tails with double stranded DNA (Okubo et al. 1964; Klumpp et al. 2010). Finally, another important lytic phages present at the fertilized maize rhizosphere that belongs to the family podoviridae are N4-like viruses. Their target bacterial hosts are gram negative bacteria in the genera (Enterobacteriaceae, Vibrionaceae, Pseudomonadaceae, Alcaligenaceae etc.). These phages possess short non-ccontractile tails, an icosahedral-head and do not require the RNA polymerase of the host bacteria for its transcription, as it have its own virus RNA polymerase (vRNAP) (Kazmierczak et al. 2002; Wittmann et al. 2015; Choi et al. 2008). Inoviruses on the other hand, belong to Inoviridae family and characterized by their cylindrical structure (filamentous) with single stranded DNA molecules that are circular in shape. They infect their hosts (Pseudomonas, Vibrio, Ralstonia and Neisseria) and do not cause lytic infection rather they establish a chronic infection and remain persistence within their bacterial hosts and release their progeny viruses without obvious harm to the infected bacteria (Roux et al. 2019; Varani et al. 2013; Bille et al. 2017).

One unique thing about lytic double stranded DNA phages described above is that they utilize holing and endolysin enzymes to penetrate, infect and lyse their hosts. The holin enzyme is responsible for digesting the bacterial cell membrane and endolysin degrade the peptidoglycan cell wall. Both enzymes enhances phage infection of the susceptible hosts' bacteria (Young and Bläsi 1995). Other viruses were detected in the fertilized soil samples but are of less importance in the ecology and evolution of bacteria in the soil. Only phages are of greater importance as they participate in the formation of disease suppressive soil, and modulation of biogeochemical cycling of nutrients in the soil. Compost manure has proven to be 
efficient in the promotion of phages abundance in the agricultural soils due to its positive effects in soil conditioning effects and reducing phage binding to clay minerals (Lawson et al. 1987).

\section{Conclusion}

This study has shown that agricultural soil precisely maize rhizosphere under organic manure fertilization enhance the proliferation of bacteriophages and bacteria as well. Virtually all bacteriophages dominant in the organic manure fertilized soils are members of Caudovirales. They are double stranded DNA viruses that cause high mortality of bacteria in the soil due to their lytic activities. The viral diversity presented here is novel and will help agriculturists to understand which fertilization approach they will adopt to ensure sustainable maintenance of crops and soil health that will translate into increased crop yield. Bacteriophages are important tools for controlling phytopathogens in the soil and should be manipulated through incorporating organic manure into the soil.

\section{Declarations}

Author contributions: NLN and MCE designed, coordinated the work, preformed experiments, analysed data, drafted and revised the manuscript.

Funding: This work was supported by the National Research Foundation of South Africa (UID 110914)

Data availability statement: The sequence data are deposited on NCBI SRA with accession number PRJNA607213

Conflict of interest: The authors have declared that no conflict of interest exists.

Ethical approval: This article does not contain any studies with human participants or animals performed by any of the authors.

Informed consent: All authors agree to publish this work.

\section{References}

Ackermann H-W (2009) Phage classification and characterization. In: Bacteriophages. Springer, pp 127140

Ackermann H-W, Krisch H (1997) A catalogue of T4-type bacteriophages. Arch Virol 142 (12):2329-2345

Adriaenssens EM, Kramer R, Van Goethem MW, Makhalanyane TP, Hogg I, Cowan DA (2017) Environmental drivers of viral community composition in Antarctic soils identified by viromics. Microbiome 5 (1):1-14 
Attai H, Brown PJ (2019) Isolation and characterization T4-and T7-like phages that infect the bacterial plant pathogen agrobacterium tumefaciens. Viruses 11 (6):528

Bille E, Meyer J, Jamet A, Euphrasie D, Barnier J-P, Brissac T, Larsen A, Pelissier P, Nassif X (2017) A virulence-associated filamentous bacteriophage of Neisseria meningitidis increases host-cell colonisation. PLoS Pathogens 13 (7):e1006495

Braga LP, Spor A, Kot W, Breuil M-C, Hansen LH, Setubal JC, Philippot L (2020) Impact of phages on soil bacterial communities and nitrogen availability under different assembly scenarios. Microbiome 8:1-14

Buttimer C, Hendrix H, Lucid A, Neve H, Noben J-P, Franz C, O’Mahony J, Lavigne R, Coffey A (2018) Novel N4-Like bacteriophages of Pectobacterium atrosepticum. Pharmaceuticals 11 (2):45

Chen L, Xun W, Sun L, Zhang N, Shen Q, Zhang R (2014) Effect of different long-term fertilization regimes on the viral community in an agricultural soil of Southern China. Eur J Soil Biol 62:121-126

Choi KH, McPartland J, Kaganman I, Bowman VD, Rothman-Denes LB, Rossmann MG (2008) Insight into DNA and protein transport in double-stranded DNA viruses: the structure of bacteriophage N4. J Mol Biol $378(3): 726-736$

Chu H, Lin X, Fujii T, Morimoto S, Yagi K, Hu J, Zhang J (2007) Soil microbial biomass, dehydrogenase activity, bacterial community structure in response to long-term fertilizer management. Soil Biol Biochem 39 (11):2971-2976

Claverie S, Ouattara A, Hoareau M, Filloux D, Varsani A, Roumagnac P, Martin DP, Lett J-M, Lefeuvre P (2019) Exploring the diversity of Poaceae-infecting mastreviruses on Reunion Island using a viral metagenomics-based approach. Scientific Rep 9 (1):1-11

Dai W, Hodes A, Hui WH, Gingery M, Miller JF, Zhou ZH (2010) Three-dimensional structure of tropismswitching Bordetella bacteriophage. Proceedings of the National Academy of Sciences 107 (9):43474352

Doan TT, Bouvier C, Bettarel Y, Bouvier T, Henry-des-Tureaux T, Janeau JL, Lamballe P, Van Nguyen B, Jouquet $P(2014)$ Influence of buffalo manure, compost, vermicompost and biochar amendments on bacterial and viral communities in soil and adjacent aquatic systems. Appl Soil Ecol 73:78-86

Emerson JB, Roux S, Brum JR, Bolduc B, Woodcroft BJ, Jang HB, Singleton CM, Solden LM, Naas AE, Boyd JA (2018) Host-linked soil viral ecology along a permafrost thaw gradient. Nat Microbiol 3 (8):870880

Enebe MC, Babalola 00 (2018) The influence of plant growth-promoting rhizobacteria in plant tolerance to abiotic stress: a survival strategy. Appl Microbiol Biotechnol 102 (18):7821-7835 
Enebe MC, Babalola $O O$ (2019) The impact of microbes in the orchestration of plants' resistance to biotic stress: a disease management approach. Appl Microbiol Biotechnol 103 (1):9-25

Enebe MC, Babalola OO (2020) Effects of inorganic and organic treatments on the microbial community of maize rhizosphere by a shotgun metagenomics approach. Ann Microbiol 70 (1):1-10

Enebe MC, Babalola 00 (2021) Soil fertilization affects the abundance and distribution of carbon and nitrogen cycling genes in the maize rhizosphere. AMB Expr 11 (1):1-10

Fiallo-Olivé E, Navas-Castillo J (2020) Molecular and Biological Characterization of a New World Mono-/Bipartite Begomovirus/Deltasatellite Complex Infecting Corchorus siliquosus. Front Microbiol 11:1755

Free A, McDonald MA, Pagaling E (2018) Diversity-function relationships in natural, applied, and engineered microbial ecosystems. Adv Appl Microbiol 105:131-189

Fuhrman JA (1999) Marine viruses and their biogeochemical and ecological effects. Nat 399 (6736):541548

Gillespie J, Opriessnig T, Meng X, Pelzer K, Buechner-Maxwell V (2009) Porcine circovirus type 2 and porcine circovirus-associated disease. J Veterinary Internal Medicine 23 (6):1151-1163

Gonzalez-Martin C, Teigell-Perez N, Lyles M, Valladares B, Griffin DW (2013) Epifluorescent direct counts of bacteria and viruses from topsoil of various desert dust storm regions. Res Microbiol 164 (1):17-21

Hammer $\varnothing$, Harper DA, Ryan PD (2001) PAST: Paleontological statistics software package for education and data analysis. Palaeontologia electronica 4 (1):9

Helsley KR, Brown TM, Furlong K, Williamson KE (2014) Applications and limitations of tea extract as a virucidal agent to assess the role of phage predation in soils. Biol Fert Soils 50 (2):263-274

Heyer R, Schallert K, Siewert C, Kohrs F, Greve J, Maus I, Klang J, Klocke M, Heiermann M, Hoffmann M (2019) Metaproteome analysis reveals that syntrophy, competition, and phage-host interaction shape microbial communities in biogas plants. Microbiome 7 (1):1-17

Hyman P, Abedon ST (2012) Smaller fleas: viruses of microorganisms. Scientifica 2012

Kazmierczak K, Davydova E, Mustaev A, Rothman-Denes L (2002) The phage N4 virion RNA polymerase catalytic domain is related to single-subunit RNA polymerases. EMBO J 21 (21):5815-5823

Kent WJ (2002) BLAT-the BLAST-like alignment tool. Genome Res 12 (4):656-664

Kimura M, Jia Z-J, Nakayama N, Asakawa S (2008) Ecology of viruses in soils: past, present and future perspectives. Soil Sci Plant Nutr 54 (1):1-32 
Klumpp J, Lavigne R, Loessner MJ, Ackermann H-W (2010) The SP01-related bacteriophages. Arch Virol 155 (10):1547-1561

Lal A, Vo TTB, Sanjaya I, Ho PT, Kim J-K, Kil E-J, Lee S (2020) Nanovirus Disease Complexes: An Emerging Threat in the Modern Era. Front Plant Sci 11:1809

Lawson KA, Barnet YM, McGilchrist CA (1987) Environmental factors influencing numbers of Rhizobium leguminosarum biovar trifolii and its bacteriophages in two field soils. Appl Environ Microbiol 53 (5):1125-1131

Liang X, Wagner RE, Zhuang J, DeBruyn JM, Wilhelm SW, Liu F, Yang L, Staton ME, Sherfy AC, Radosevich M (2019) Viral abundance and diversity vary with depth in a southeastern United States agricultural ultisol. Soil Biol Biochem 137:107546

Marcó MB, Reinheimer J, Quiberoni A (2015) Phage adsorption and lytic propagation in Lactobacillus plantarum: Could host cell starvation affect them? BMC Microbiol 15 (1):1-7

Meyer F, Paarmann D, D'Souza M, Olson R, Glass EM, Kubal M, Paczian T, Rodriguez A, Stevens R, Wilke A (2008) The metagenomics RAST server-a public resource for the automatic phylogenetic and functional analysis of metagenomes. BMC Bioinformatics 9 (1):386

Miller ES, Kutter E, Mosig G, Arisaka F, Kunisawa T, Rüger W (2003) Bacteriophage T4 genome. Microbiol Mol Biol Rev 67 (1):86-156

Musyimi D, Juma E, Opande G (2018) Enumeration and identification of rhizospheric microorganisms of sugarcane variety CO 421 in kibos, Kisumu County, Kenya.

Narr A, Nawaz A, Wick LY, Harms H, Chatzinotas A (2017) Soil viral communities vary temporally and along a land use transect as revealed by virus-like particle counting and a modified community fingerprinting approach (fRAPD). Front Microbiol 8:1975

Okubo S, Strauss B, Stodolsky M (1964) The possible role of recombination in the infection of competent Bacillus subtilis by bacteriophage deoxyribonucleic acid. Virol 24 (4):552-562

Pajunen MI, Elizondo MR, Skurnik M, Kieleczawa J, Molineux IJ (2002) Complete nucleotide sequence and likely recombinatorial origin of bacteriophage T3. J Mol Biol 319 (5):1115-1132

Palaniveloo K, Amran MA, Norhashim NA, Mohamad-Fauzi N, Peng-Hui F, Hui-Wen L, Kai-Lin Y, Jiale L, Chian-Yee MG, Jing-Yi L (2020) Food waste composting and microbial community structure profiling. Processes 8 (6):723

Philippot L, Raaijmakers JM, Lemanceau P, Van Der Putten WH (2013) Going back to the roots: the microbial ecology of the rhizosphere. Nat Rev Microbiol 11 (11):789-799 
Rabiey M, Roy SR, Holtappels D, Franceschetti L, Quilty BJ, Creeth R, Sundin GW, Wagemans J, Lavigne R, Jackson RW (2020) Phage biocontrol to combat Pseudomonas syringae pathogens causing disease in cherry. Microbial Biotechnol 13 (5):1428-1445

Ramírez M, Neuman BW, Ramírez CA (2020) Bacteriophages as promising agents for the biological control of moko disease (Ralstonia solanacearum) of banana. Biological Control 149:104238

Robilotti E, Deresinski S, Pinsky BA (2015) Norovirus. Clin Microbiol Rev 28 (1):134-164

Roux S, Krupovic M, Daly RA, Borges AL, Nayfach S, Schulz F, Sharrar A, Carnevali PBM, Cheng J-F, Ivanova NN (2019) Cryptic inoviruses revealed as pervasive in bacteria and archaea across Earth's biomes. Nat Microbiol 4 (11):1895-1906

Six J, Bossuyt H, Degryze S, Denef K (2004) A history of research on the link between (micro) aggregates, soil biota, and soil organic matter dynamics. Soil and Tillage Research 79 (1):7-31

Smith MC, Burns RN, Wilson SE, Gregory MA (1999) The complete genome sequence of the Streptomyces temperate phage $\varphi C 31$ : evolutionary relationships to other viruses. Nucleic acids Res 27 (10):2145-2155

Srinivasiah S, Lovett J, Ghosh D, Roy K, Fuhrmann JJ, Radosevich M, Wommack KE (2015) Dynamics of autochthonous soil viral communities parallels dynamics of host communities under nutrient stimulation. FEMS Microbiol Ecol 91 (7)

Suárez JE, Clayton TM, Rodríguez A, Bibb MJ, Chater KF (1992) Global transcription pattern of $\pi \mathrm{C} 31$ after induction of a Streptomyces coelicolor lysogen at different growth stages. Microbiol 138 (10):2145-2157

Sváb D, Falgenhauer L, Rohde M, Szabó J, Chakraborty T, Tóth I (2018) Identification and characterization of T5-like bacteriophages representing two novel subgroups from food products. Front Microbiol 9:202

Tétart F, Desplats C, Kutateladze M, Monod C, Ackermann H-W, Krisch H (2001) Phylogeny of the major head and tail genes of the wide-ranging T4-type bacteriophages. J Bacteriol 183 (1):358-366

Trubl G, Jang HB, Roux S, Emerson JB, Solonenko N, Vik DR, Solden L, Ellenbogen J, Runyon AT, Bolduc B (2018) Soil viruses are underexplored players in ecosystem carbon processing. MSystems 3 (5)

Van Etten JL, Agarkova IV, Dunigan DD (2020) Chloroviruses. Viruses 12 (1):20

Varani AM, Monteiro-Vitorello CB, Nakaya HI, Van Sluys M-A (2013) The role of prophage in plantpathogenic bacteria. Ann Rev phytopathol 51:429-451

Wilke A, Harrison T, Wilkening J, Field D, Glass EM, Kyrpides N, Mavrommatis K, Meyer F (2012) The M5nr: a novel non-redundant database containing protein sequences and annotations from multiple sources and associated tools. BMC bioinformatics 13 (1):141 
Williamson KE, Fuhrmann JJ, Wommack KE, Radosevich M (2017) Viruses in soil ecosystems: an unknown quantity within an unexplored territory. Ann Rev Virol 4:201-219

Williamson KE, Radosevich M, Wommack KE (2005) Abundance and diversity of viruses in six Delaware soils. Appl Environ Microbiol 71 (6):3119-3125

Wittmann J, Klumpp J, Switt AIM, Yagubi A, Ackermann H-W, Wiedmann M, Svircev A, Nash JH, Kropinski AM (2015) Taxonomic reassessment of N4-like viruses using comparative genomics and proteomics suggests a new subfamily-“Enquartavirinae”. Arch Virol 160 (12):3053-3062

Woodcroft BJ, Singleton CM, Boyd JA, Evans PN, Emerson JB, Zayed AA, Hoelzle RD, Lamberton TO, McCalley CK, Hodgkins SB (2018) Genome-centric view of carbon processing in thawing permafrost. Nat 560 (7716):49-54

Young R, Bläsi U (1995) Holins: form and function in bacteriophage lysis. FEMS Microbiol Rev 17 (12):191-205

Yu X, Xu Y, Gu Y, Zhu Y, Liu X (2017) Characterization and genomic study of “phiKMV-Like” phage PAXYB1 infecting Pseudomonas aeruginosa. Scientific Rep 7 (1):1-13

Zaczek-Moczydłowska MA, Young GK, Trudgett J, Plahe C, Fleming CC, Campbell K, O’Hanlon R (2020) Phage cocktail containing Podoviridae and Myoviridae bacteriophages inhibits the growth of Pectobacterium spp. under in vitro and in vivo conditions. PloS One 15 (4):e0230842

Zhang Q-C, Shamsi IH, Xu D-T, Wang G-H, Lin X-Y, Jilani G, Hussain N, Chaudhry AN (2012) Chemical fertilizer and organic manure inputs in soil exhibit a vice versa pattern of microbial community structure. Appl Soil Ecol 57:1-8

Zhang Q, Sun J, Liu S, Wei Q (2013) Manure refinement affects apple rhizosphere bacterial community structure: a study in sandy soil. PloS one 8 (10)

Zheng T, Li J, Ni Y, Kang K, Misiakou M-A, Imamovic L, Chow BK, Rode AA, Bytzer P, Sommer M (2019) Mining, analyzing, and integrating viral signals from metagenomic data. Microbiome 7 (1):1-15

Zhuang J, Jin Y (2003) Virus retention and transport as influenced by different forms of soil organic matter. J Environ Qual 32 (3):816-823

Zivanovic Y, Confalonieri F, Ponchon L, Lurz R, Chami M, Flayhan A, Renouard M, Huet A, Decottignies P, Davidson AR (2014) Insights into bacteriophage T5 structure from analysis of its morphogenesis genes and protein components. J Virol 88 (2):1162-1174

\section{Table}


Table 1. Bacteriophage families' diversity indexes from maize rhizosphere samples under fertilization Cn0 (control), N1 (60 kg/ha NPK), N2 (120 kg/ha NPK), Cp8 (8 tons/ha compost), and Cp4 (4 tons/ha compost manure)

\begin{tabular}{|lllllll|}
\hline & Cp8 & Cp4 & N2 & N1 & Cn0 & P value \\
\hline Simpson_1-D & 0.2485 & 0.006921 & 0.004417 & 0.5148 & 0.5683 & 0.5242 \\
\hline Shannon_H & 0.5346 & 0.02587 & 0.01813 & 0.9108 & 0.9996 & \\
\hline Evenness_e^H/S & 0.3414 & 0.2052 & 0.2037 & 0.4973 & 0.5434 & \\
\hline
\end{tabular}

\section{Figures}

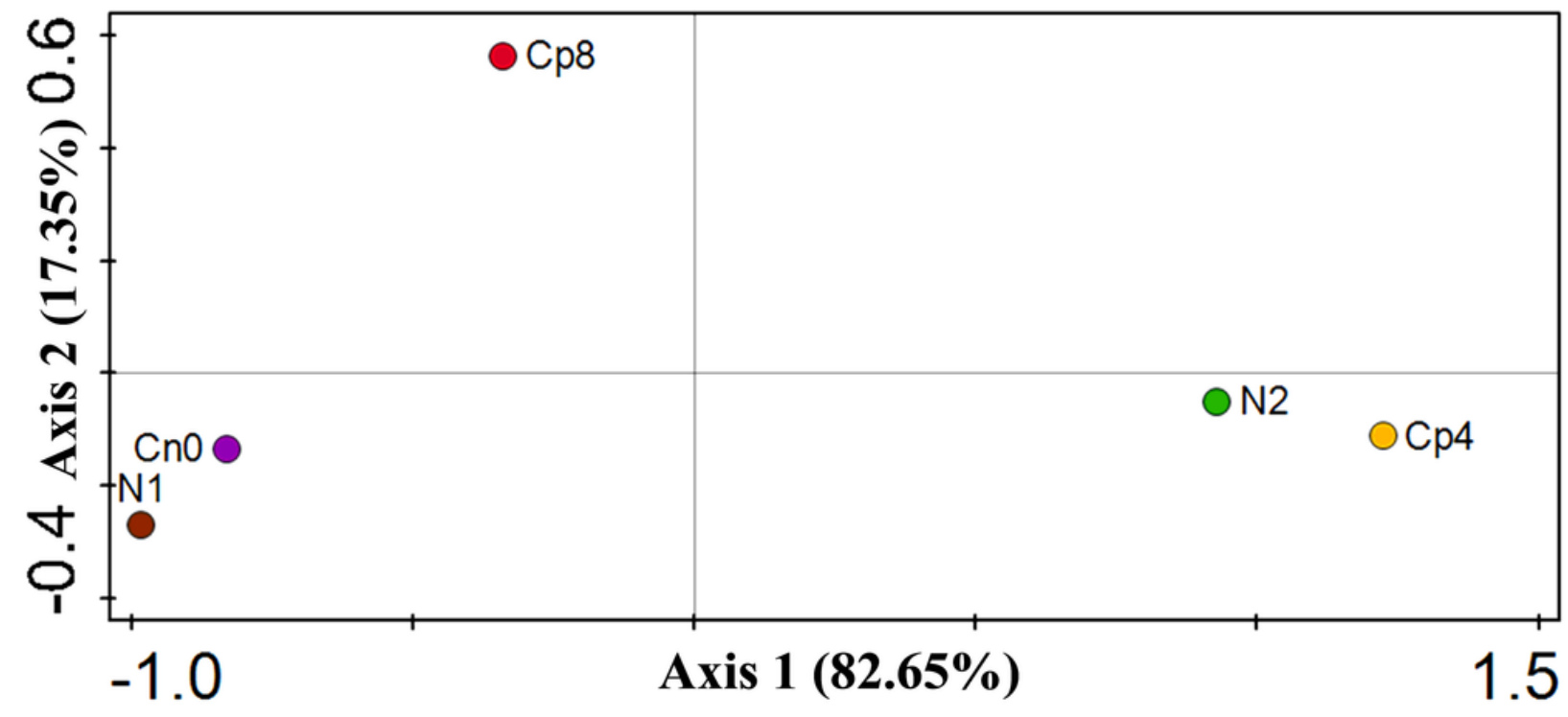

Figure 1

Principal coordinate analysis of the abundant viral genus present in the maize rhizosphere soil under fertilization. Cn0 (control), N1 (60 kg/ha NPK), N2 (120 kg/ha NPK), Cp8 (8 tons/ha compost), and Cp4 (4 tons/ha compost manure) 


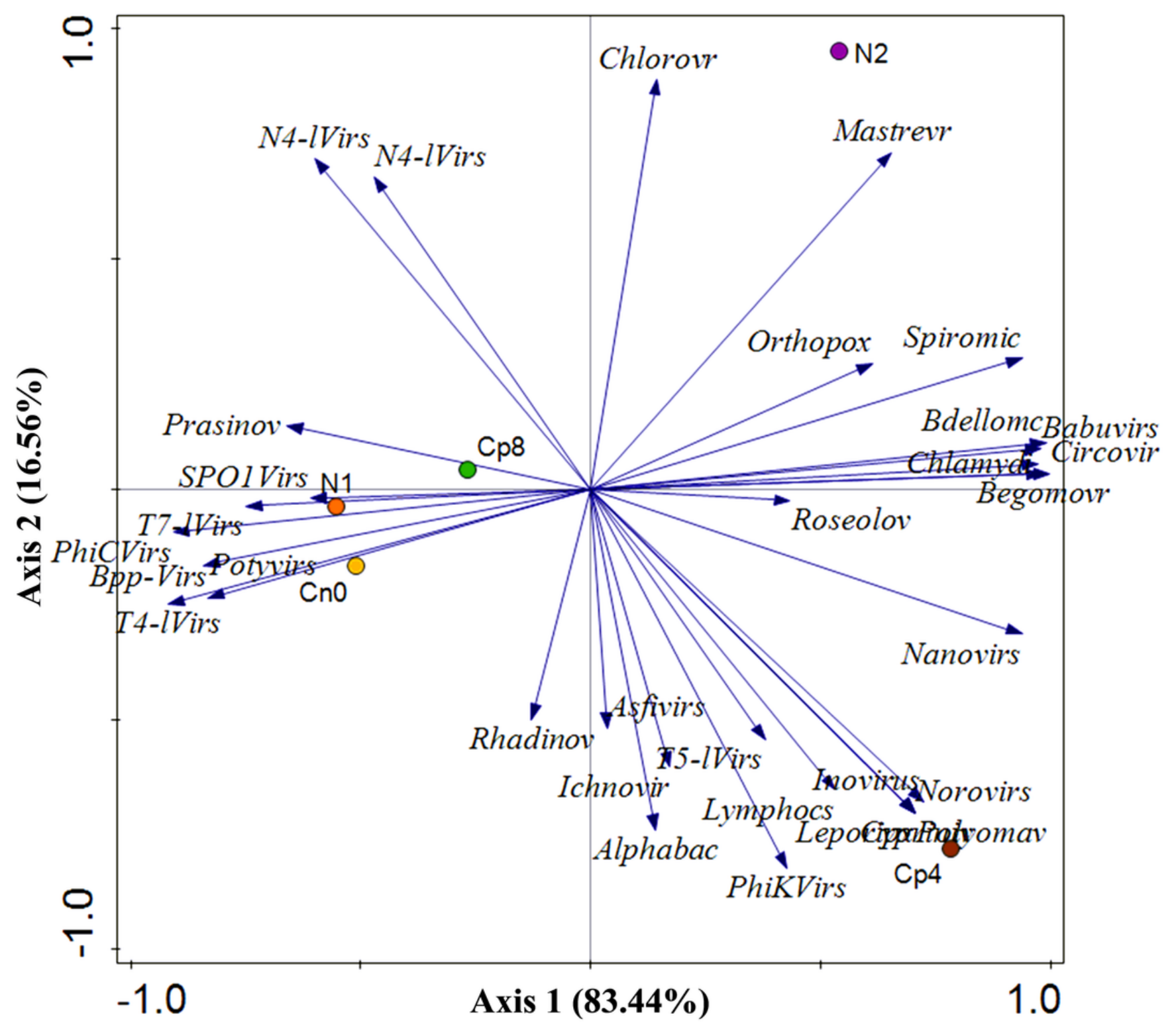

Figure 2

The PCA-Principal component analysis of the most abundant viral genus in the rhizosphere of maize under fertilization. Cn0 (control), N1 (60 kg/ha NPK), N2 (120 kg/ha NPK), Cp8 (8 tons/ha compost), and Cp4 (4 tons/ha compost manure) 


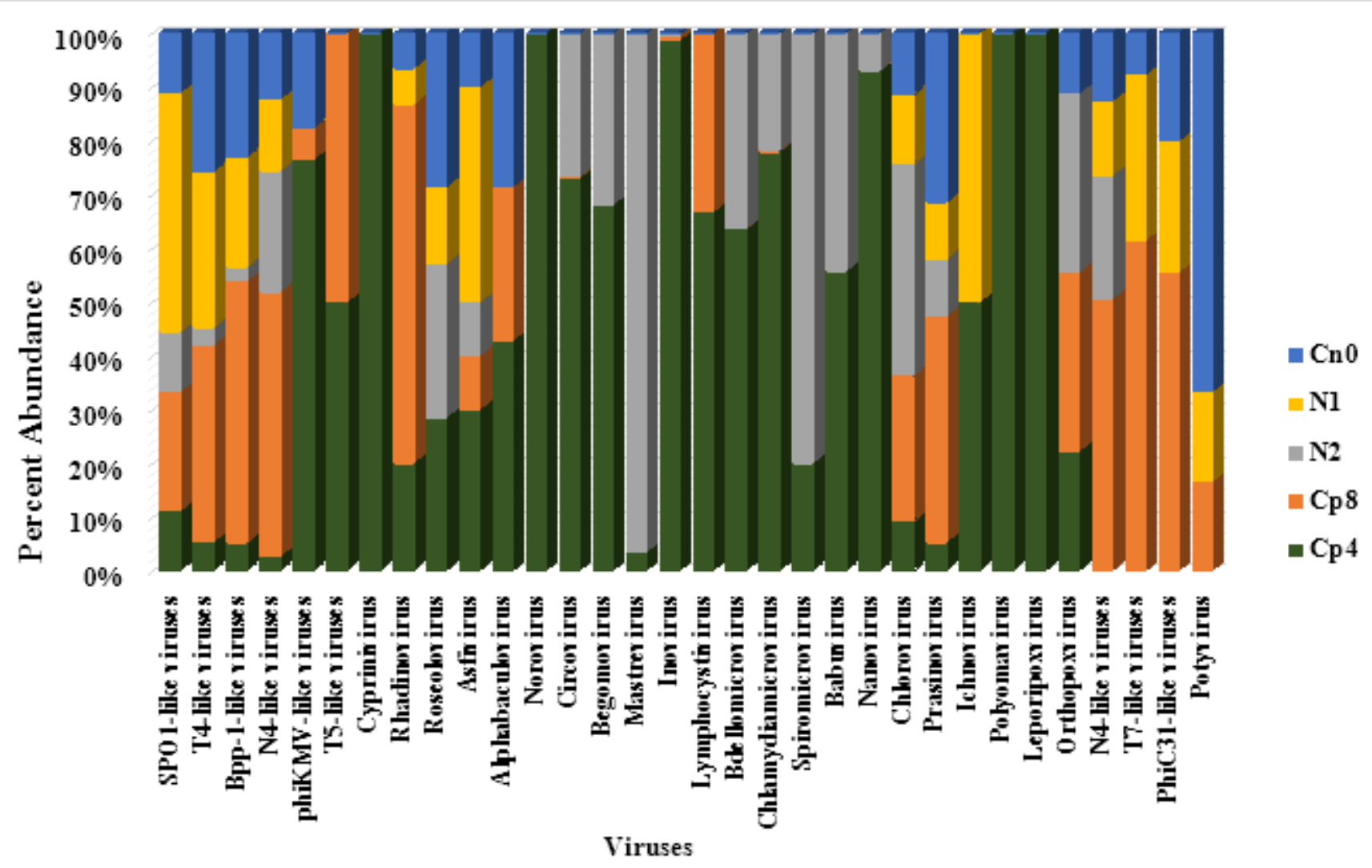

Figure 3

Percent abundance of viral genus present in the rhizosphere soils of maize fertilized with organic and inorganic fertilization. Cn0 (control), N1 (60 kg/ha NPK), N2 (120 kg/ha NPK), Cp8 (8 tons/ha compost), and $\mathrm{Cp} 4$ (4 tons/ha compost manure) 

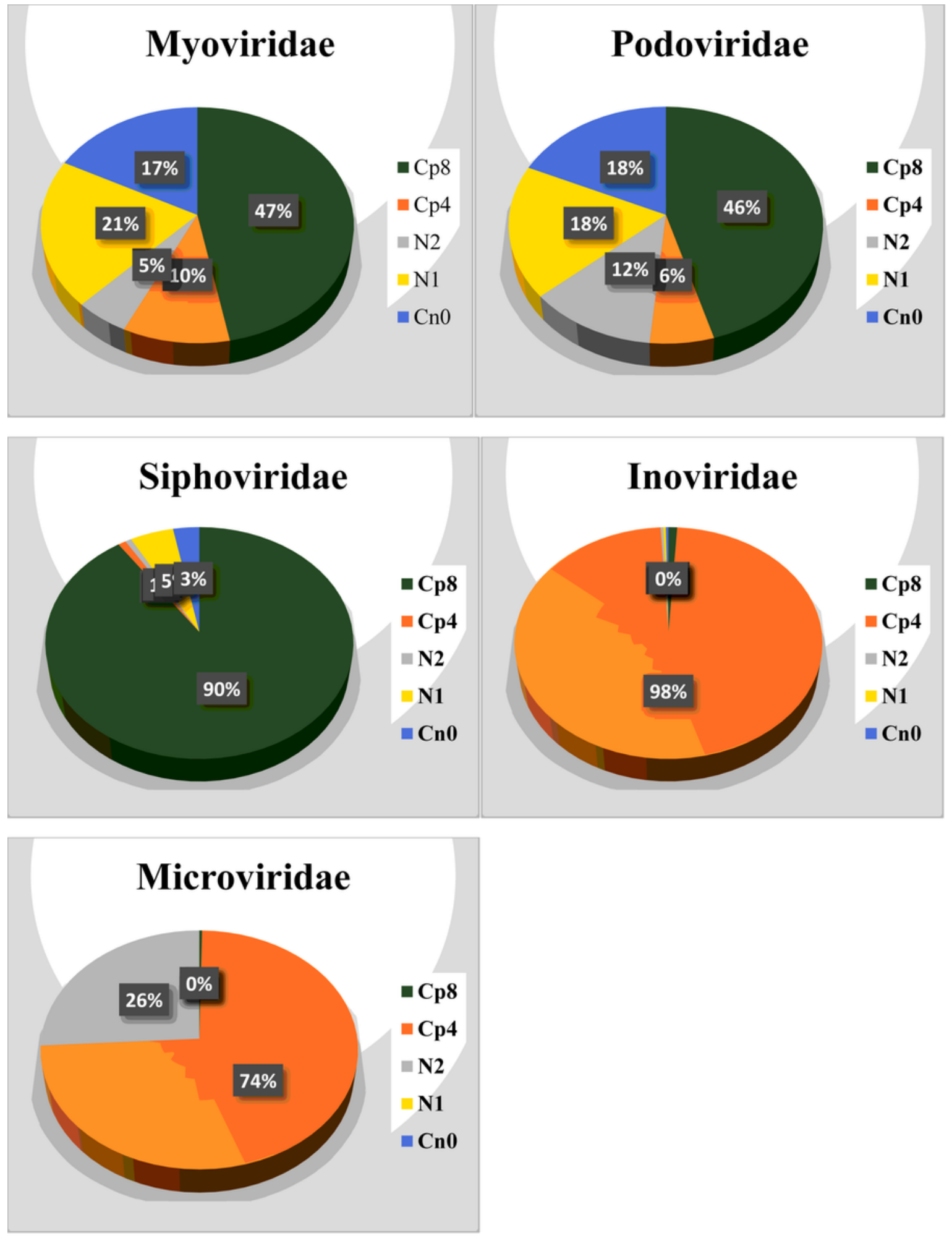

Figure 4

Bacteriophage families' frequency distribution within the maize rhizosphere under fertilization. Cn0 (control), N1 (60 kg/ha NPK), N2 (120 kg/ha NPK), Cp8 (8 tons/ha compost), and Cp4 (4 tons/ha compost manure) 


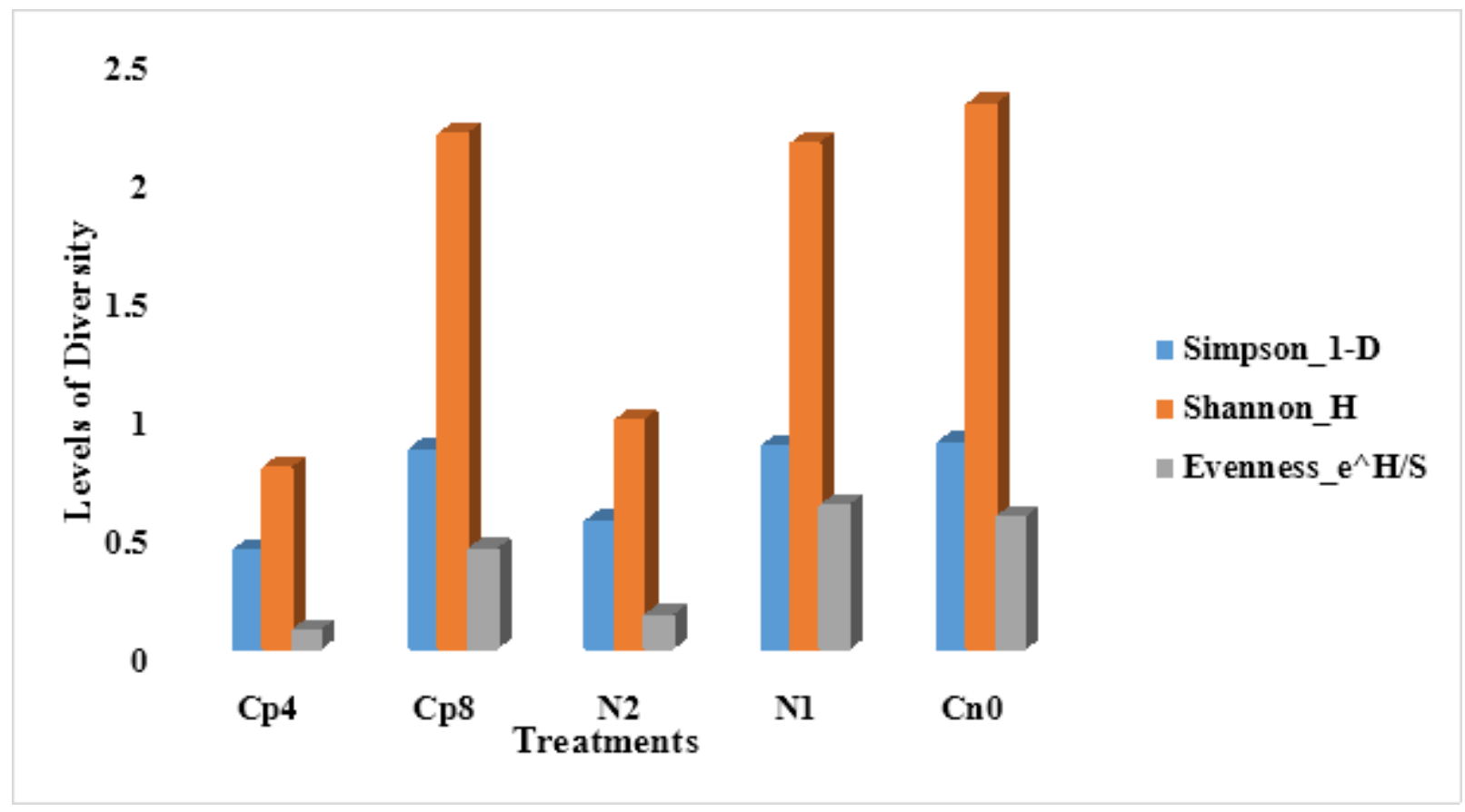

Figure 5

Diversity indices of abundance viral genus present in the maize rhizosphere under fertilization $\mathrm{Cn} 0$ (control), N1 (60 kg/ha NPK), N2 (120 kg/ha NPK), Cp8 (8 tons/ha compost), and Cp4 (4 tons/ha compost manure) 